\title{
Vínculos do binômio criança-família antes e após o diagnóstico de câncer infantil ${ }^{\star}$
}

Bonds of the child-family binomial before and after the diagnosis of childhood cancer

Vínculos del binomio niño-familia antes y después del diagnóstico de cáncer infantil

\section{Juliana Amaral Rockembach ${ }^{\mathrm{I}}$, Rosani Manfrin Muniz ${ }^{\mathrm{II}}$, Michele Cristiene Nachtigall Barboza ${ }^{\mathrm{III}}$, Aline Blaas Schiavon ${ }^{\mathrm{IV}}$, Bruna Knob Pintov ${ }^{\mathrm{v}}$, Franciele Budziareck das Neves ${ }^{\mathrm{VI}}$}

\begin{abstract}
Resumo: Objetivo: descrever e analisar os vínculos do binômio criança-família, antes e após o diagnóstico de câncer. Métodos: estudo qualitativo e descritivo realizado com seis famílias de crianças com câncer. A coleta de dados ocorreu com questões norteadoras, construção de Genograma e Ecomapa, de julho a outubro de 2017 nos domicílios dos participantes. Realizou-se a análise temática de Braun e Clarke. Resultados: os resultados foram os vínculos rompidos e os criados antes e após o câncer. Os principais vínculos rompidos foram as atividades escolares, os passeios, o convívio com o animal de estimação e as mudanças na alimentação. Os vínculos criados foram as novas amizades no hospital e a utilização de brincadeiras e jogos eletrônicos. Conclusão: as atividades lúdicas mostraram-se como um interessante instrumento de trabalho a ser utilizado pelos profissionais de saúde, auxiliando na construção de vínculos, no enfrentamento e na adaptação da criança e da família.
\end{abstract}

Descritores: Oncologia; Família; Pediatria; Criança; Pesquisa Qualitativa

Abstract: Objective: to describe and analyze the bonds of the child-family binomial, before and after the diagnosis of cancer. Methods: This is a qualitative and descriptive study conducted with six families of children with cancer.

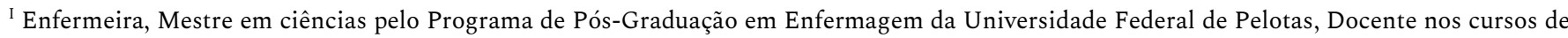
Graduação em Enfermagem e Fisioterapia- Faculdade Dom Alberto, Santa Cruz do Sul, Rio Grande do Sul, Brasil. E-mail: ju.rockembach@hotmail.com. Orcid: https://orcid.org/0000-0002-0693-8775

II Enfermeira, Doutora em enfermagem, Professora do Programa de Pós-Graduação em Enfermagem da Universidade Federal de Pelotas, Pelotas, Rio Grande do Sul, Brasil. E-mail: romaniz@terra.com.br. Orcid: https://orcid.org/0000-0002-5642-7842

III Enfermeira, Doutora em ciências pelo Programa de Pós-Graduação em Enfermagem da Universidade Federal de Pelotas, Docente da Faculdade de Enfermagem da Universidade Federal de Pelotas, Pelotas, Rio Grande do Sul, Brasil. E-mail: michelenachtigall@yahoo.com.br. Orcid: https://orcid.org/0000-0003-1489-5813

IV Enfermeira, Mestre em ciências pelo Programa de Pós-Graduação em Enfermagem da Universidade Federal de Pelotas, Enfermeira da Prefeitura de Canguçu, Canguçu, Rio Grande do Sul, Brasil. E-mail: aline-schiavon@hotmail.com. Orcid: https://orcid.org/0000-0001-6344-4360

V Enfermeira. Doutora em ciências pelo Programa de Pós-Graduação em Enfermagem da Universidade Federal de Pelotas, Enfermeira da Prefeitura de Capão do Leão, Capão do Leão, Rio Grande do Sul, Brasil. E-mail: brunaknob@hotmail.com. Orcid: https://orcid.org/0000-0002-8877-8874

VI Enfermeira, Doutoranda em Enfermagem - Programa de Pós-Graduação em Enfermagem da Universidade Federal de Santa Catarina. Florianópolis, Santa Catarina, Brasil. E-mail: fran.bnvs@gmail.com. Orcid: https://orcid.org/0000-0002-2015-9153
}

*Extraído da dissertação "Atividades Lúdicas no contexto domiciliar de crianças com câncer e sua família", Programa de Pós-Graduação em Enfermagem, Universidade Federal de Pelotas, 2018. 
Data collection occurred with guiding questions, construction of Genogram and Ecomap, from July to October 2017 in the participants' homes. Thematic analysis by Braun and Clarke was carried out. Results: The results were the broken bonds and those created before and after cancer. The main broken bonds were school activities, walks, living with the pet, and changes in food. The bonds created were new friendships in the hospital and the use of games and electronic games. Conclusion: recreational activities proved to be an interesting work tool to be used by health professionals, helping to build bonds, coping, and adapting the child and family.

Descriptors: Medical Oncology; Family; Pediatrics; Child; Qualitative Research

Resumen: Objetivo: describir y analizar los vínculos del binomio niño-familia, antes y después del diagnóstico de cáncer. Métodos: estudio cualitativo y descriptivo realizado con seis familias de niños con cáncer. La recolección de datos tuvo preguntas guiadoras, construcción de Genograma y Ecomapa, de julio a octubre de 2017 en los domicilios de los participantes. Se realizó el análisis temático de Braun y Clarke. Resultados: los resultados fueron los vínculos rotos y los creados antes y después del cáncer. Los principales vínculos rotos fueron las actividades escolares, los paseos, la convivencia con el animal de estimación y los cambios en la alimentación. Los vínculos creados fueron las nuevas amistades en el hospital y la utilización de juegos y electrónicos. Conclusión: las actividades lúdicas se mostraron como un interesante instrumento de trabajo a ser utilizado por los profesionales de salud, auxiliando en la construcción de vínculos, en el enfrentamiento y en la adaptación del niño y l familia.

Descriptores: Oncología Médica; Familia; Pediatría; Niño; Investigación Cualitativa

\section{Introdução}

O câncer infantojuvenil, que ocorre na criança e no adolescente (entre 0 e 19 anos), consiste em um conjunto de doenças que apresentam características próprias em relação à histopatologia e ao comportamento clínico e pode ocorrer em qualquer local do organismo. Diferentemente do câncer do adulto, esse tipo de câncer é predominantemente de natureza embrionária e, geralmente, afeta as células do sistema sanguíneo e os tecidos de sustentação, sendo os tipos predominantes de cânceres pediátricos a leucemia (28\%), o câncer no sistema nervoso central (26\%) e os linfomas $(8 \%)$. Os fatores de risco relacionados com o estilo de vida não influenciam o risco de uma criança desenvolver câncer e raramente ela pode apresentar alterações genéticas que as tornem propensas a desenvolver certo tipo de câncer. ${ }^{1}$

O número de novos casos de câncer infantojuvenil esperados para o Brasil, para cada ano do triênio 2020-2022, é de 4.310 casos novos quando considerado o sexo masculino e de 4.150 considerando o sexo feminino. Esses valores correspondem a um risco estimado de 137,87 novos casos por milhão no sexo masculino, e de 139,04 por milhão para o sexo feminino. O progresso do 
tratamento tem sido satisfatório nas últimas décadas, de modo que, atualmente, $80 \%$ das crianças podem ser curadas, se diagnosticadas precocemente, e tratadas em centros especializados. ${ }^{1}$

Apesar das chances de um bom prognóstico, o diagnóstico de câncer está cercado de estigmas e significados simbólicos relacionados à dor, ao sofrimento e à morte. Ao vivenciar uma doença crônica, como o câncer, com um de seus membros, a família passa por uma série de alterações, como o aumento dos gastos devido à hospitalização, ao transporte e à hospedagem, já que, por vezes, o provedor da família é o mesmo que irá cuidar da criança, além da desorganização da rotina familiar devido às responsabilidades acrescidas. Como consequência disso, há o surgimento de sentimentos, como o medo, a ansiedade e a insegurança que a família e a criança experenciam durante todo o processo, desde o diagnóstico, o processo de tratamento até a recuperação. ${ }^{2}$ Nesse sentido, reflexões e adaptações se mostram importantes para a nova realidade que a família enfrenta, sendo necessários inúmeros ajustes, organizações e redefinições de papéis para preservar o equilíbrio familiar.

O câncer na criança é uma doença que requer vários momentos de internação, pois ela sai de seu lar e do convívio com seus familiares para adaptar-se ao ambiente hospitalar e a tudo que o envolve. Nesse sentido, o adoecimento e a hospitalização de uma criança correspondem à rupturas em seu cotidiano e de sua família, visto que passa a estar em um local limitado, no qual as rotinas hospitalares e o próprio ambiente diminuem a quantidade e a variedade de atividades com as quais estava habituada a executar, o que pode interromper o seu desenvolvimento natural. ${ }^{3}$

Desta forma, os vínculos construídos antes e após a internação podem resultar em mudanças que alteram a dinâmica no cotidiano da criança e no seu desenvolvimento. Entendese por vínculo apoiador aquelas pessoas que poderão participar de dois ou de mais sistemas, formando um elo, o que facilita no processo de resolução das crises geradas pela/e na família. ${ }^{4}$

Assim sendo, o vínculo constitui-se como uma importante estratégia para a adesão e a qualidade dos cuidados prestados à criança e à família, já que é a partir dessa rede de relações 
que os vínculos com vizinhos, comunidade, escola e hospital, poderão, ou não, potencializar o processo de desenvolvimento da criança com câncer e da própria família na realização e na busca por práticas de cuidados. ${ }^{4}$

Para tanto, considera-se que para descrever e analisar as alterações na dinâmica da criança e família tem-se o Genograma e o Ecomapa como instrumentos que podem ser utilizados como estratégias de visualização da conformação familiar e dos vínculos que essa família e criança estabelecem em sua vida, entre si e fora dela. Cabe considerar que o Genograma é uma representação gráfica da composição familiar e dos relacionamentos básicos em, pelo menos, três gerações, elaborado por meio de símbolos. ${ }^{5}$ Já o Ecomapa é um diagrama das relações entre a família e a comunidade, e visa auxiliar na avaliação dos apoios disponíveis e na sua utilização pela família. Esse último pode representar a presença ou a ausência de recursos sociais, culturais e econômicos, sendo o retrato de um determinado momento na vida dos membros da família. ${ }^{6}$ Esses instrumentos são utilizados na área da saúde, incluindo a enfermagem, como uma forma de representar os processos familiares estruturais, emocionais e afetivos.

A partir do exposto, a proposta da pesquisa estudo torna-se relevante uma vez que direciona para as dificuldades advindas do diagnóstico, do tratamento e do impacto do câncer na infância para a criança e sua família, além do contexto hospitalar. Portanto, o objetivo do estudo se centra em descrever e analisar os vínculos do binômio criança-família, antes e após o diagnóstico de câncer.

\section{Método}

O presente estudo tem uma abordagem qualitativa e descritiva, com foco na interação lúdica entre a família e a criança com câncer a partir da construção de Genograma e de Ecomapa. Para tanto, foi realizado em um município do sul do Rio Grande do Sul (RS), de julho a outubro de 2017. Cabe referir que a cidade na qual o estudo ocorreu não é tida como referência 
5 | Rockembach JA, Muniz RM, Barboza MCN, chiavon AB, Pinto BK, Neves FB

para o tratamento oncológico em crianças, e, por isso, os participantes da pesquisa viajavam para a capital do estado, Porto Alegre, para a realização de quimioterapia e dos acompanhamentos médicos, permanecendo, nos demais períodos do tratamento, em suas residências na cidade em que este estudo foi aplicado.

Para a pesquisa foram adotados como critérios de inclusão das crianças os seguintes fatores: a) ter entre 04 e 12 anos; b) não estar em internação hospitalar na cidade na qual realizavam o tratamento durante a coleta de dados; c) ter recebido o diagnóstico de qualquer tipo de câncer; d) estar em condições físicas e psicológicas para participar do estudo; e, ainda, e) residir na cidade na qual o estudo foi desenvolvido, ou em cidades distantes até 50 quilometros. Os critérios de inclusão dos familiares foram: a) ser familiar de criança com idade entre 04 e 12 anos que tenha diagnóstico de câncer; e, b) aceitar a sua participação nas atividades propostas e ter plena e total concordância sobre a participação da criança no estudo. Como critério de exclusão da pesquisa, adotou-se somente as crianças em cuidados paliativos.

Seguindo esses critérios, a primeira família contatada foi indicada pelo Serviço de Oncologia de referência. As demais foram identificadas por meio da técnica snowball (bola de neve), ${ }^{7}$ que consiste em uma amostra não probabilística e não feita por conveniência, em que os participantes iniciais indicam novos casos, e esses também indicarão outros participantes, sucessivamente, até que não haja novas indicações.

Dessa forma, a Família 01 indicou novos participantes, e as famílias seguintes indicaram outras famílias a participarem do estudo. O ponto de saturação foi quando a última indicou somente famílias que já haviam sido contatadas para fazer parte do estudo. Por fim, foram indicadas um total de 08 famílias, e, dessas, 06 aceitaram participar do estudo. Ressalta-se que 01 família negou devido ao fato de a criança estar se recuperando de um transplante de medula óssea e 01 família não respondeu ao convite. Das 06 famílias, obteve-se um total de 18 membros que participaram da presente pesquisa. 
Vínculos do binômio criança-família antes e após o diagnóstico de câncer infantil | 6

Assim, a pesquisadora realizou um contato prévio com as famílias por telefone, explicou os objetivos da pesquisa e, após o aceite, agendou a coleta no próprio domicílio dos participantes. Os instrumentos de coleta de dados utilizados foram, conforme já especificado, o Genograma e o Ecomapa, sendo aplicados pela pesquisadora principal do estudo. Para tanto, a pesquisadora recebeu um treinamento para a coleta de dados durante oficinas oferecidas ao longo de seu curso de Mestrado.

Logo, o Genograma foi construído em conjunto com a família, utilizando desenhos que representaram de forma lúdica os membros e os vínculos estabelecidos entre eles. Já o Ecomapa foi produzido em cartolina, com a família no centro e, ao redor, os familiares desenharam, escreveram ou representaram com brinquedos quais eram as suas principais redes de apoio, bem como as atividades lúdicas (AL), os vínculos perdidos, os vínculos criados e/ou fortalecidos durante esse processo. A construção do Genograma e do Ecomapa foi realizada pelos membros da família de forma conjunta. Os desenhos e os símbolos dos Genogramas e dos Ecomapas foram fotografados e anexados ao estudo sob forma de imagem.

Para a realização dos desenhos, foi apresentada para as famílias uma legenda representada por: a) uma linha reta como vínculo fraco; b) duas linhas retas como vínculo moderado; c) três linhas retas como vínculo forte; d) uma linha sinuosa representando o vínculo conflituoso; e) uma linha vermelha transversal caracterizando o vínculo pouco interrompido; f) duas linhas vermelhas como vínculo parcialmente interrompido; e, por fim, g) três linhas vermelhas como vínculo rompido. Durante a construção do Genograma e do Ecomapa foram propostas às famílias as seguintes questões norteadoras: a) represente como era, em um momento anterior ao diagnóstico, o seu dia a dia e o de seu filho?; b) como eram as brincadeiras da criança antes do diagnóstico?; c) o que a família costumava fazer para se divertir antes do diagnóstico?; c) como é a rotina de brincadeiras e de lazer agora?; d) como você se sente brincando com o seu filho neste período pós diagnóstico?; e) desenhem as atividades que não 
são mais realizadas; e, f) quais brincadeiras e atividades de lazer vocês gostariam de voltar a realizar? A proposição de ambas as atividades teve, em média, um tempo de duração de duas horas. Mostra-se importante referir que as falas dos participantes durante a construção do Genograma e do Ecomapa foram gravadas com aparelho de áudio.

Os princípios éticos considerados para realização deste trabalho foram assegurados conforme a Resolução nº 466/2012, do Conselho Nacional de Saúde do Ministério da Saúde, ${ }^{8}$ e da Resolução do Conselho Federal de Enfermagem (COFEN) 311/2007. ${ }^{9}$ Este estudo obteve aprovação do Comitê de Ética em Pesquisa sob o parecer número 2.130.783, em 21 de junho de 2017. Ainda, as crianças participantes da pesquisa assinaram o Termo de Assentimento Livre e Esclarecido e os familiares assinaram o Termo de Consentimento Livre e Esclarecido, que foram elaborados em duas vias, ficando uma cópia com os participantes e outra com a pesquisadora. Ademais, as famílias participantes foram identificadas por numerais, e os indivíduos que compõe cada família foram identificados por meio de nomes fictícios. Exemplo: João, pai da Família 01, Maria, filha da família 02.

A análise dos dados obtidos na pesquisa foi realizada com base na proposta de Análise Temática, contemplando suas seis fases. ${ }^{10}$ Os dados gravados em áudio foram transcritos na íntegra, lidos e relidos, objetivando a familiarização com os mesmos conforme a fase 1 da análise. As fases seguintes foram realizadas por meio do uso do software Ethnograph, a fim de auxiliar no processo de geração de códigos (fase 2), procura e revisão de temas (fase 3 e 4) e definição dos temas (fase 5). Após essas etapas, o relatório final (fase 6) foi elaborado de acordo com os temas construídos a partir do agrupamento dos códigos com os principais resultados da pesquisa.

\section{Resultados}




\section{Família 01}

Família composta por Bianca, cinco anos, sua irmã Bárbara, de 10 anos, sua mãe Beatriz, 41 anos, e Beto, pai, 40 anos. Bianca foi diagnosticada com Leucemia Linfoide Aguda em 2016, aos quatro anos de idade. Ambos os pais eram professores, porém a mãe teve que se afastar do trabalho para poder acompanhar a filha durante o tratamento. Bianca passava dias em Porto Alegre (RS) e outros dias em sua residência. Após o diagnóstico de Bianca, as AL da Família 01 mudaram, os vínculos foram interrompidos e outros fortalecidos, conforme expresso no Ecomapa (Figura 1) desenvolvido pela família, sendo que Bianca e Bárbara desenharam e seus pais ajudaram a escrever.

Figura 1- Ecomapa família 01.

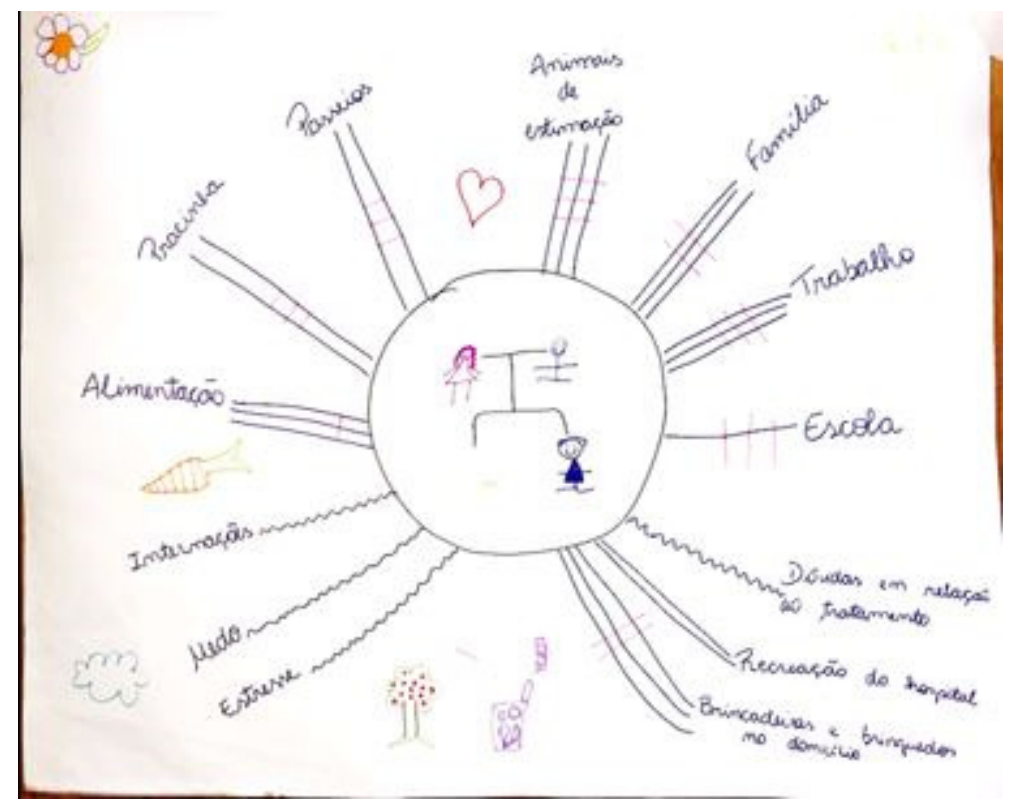

No Ecomapa da Família 01, verificam-se as AL que sofreram mudanças depois do diagnóstico, em que passeios e encontros com os outros parentes deram espaço ao vínculo conflituoso/estressante com as internações, o medo, o estresse e todas as dúvidas relacionadas ao tratamento. Os pais também tiveram mudanças em suas atividades e expressaram o vínculo com o trabalho que precisou ser interrompido. Além disso, Bianca teve que parar de frequentar a escola que estava apenas há dois meses, vínculo fraco que ainda estava se fortalecendo, mas que teve que ser interrompido após o diagnóstico. 
A Família 01 também desenhou o vínculo forte com os animais de estimação que teve que ser interrompido devido ao tratamento de Bianca. Por medo de que os animais causassem algum malefício para a menina, os pais decidiram doá-los para outra família. A alimentação foi outro ponto trazido pela família ao falar dos vínculos interrompidos após o diagnóstico. Desenhando uma cenoura, Bianca e Bárbara contaram que tiveram que tirar os vegetais crus e as frutas da alimentação da família.

Em relação as AL que envolvem brincadeiras, a Família 01 relatou o vínculo moderado com a recreação no hospital, pois nem sempre Bianca sentia ânimo para brincar. Quando voltava para o domicílio, a Família 01 considerou que o vínculo com as brincadeiras foi interrompido em partes, pois Bianca tem limitações físicas relacionadas ao tratamento. Dentre todos os vínculos interrompidos na Família 01, brincar na praça foi a atividade que Bianca relatou sentir mais falta.

\section{Família 02}

A Família 02 é composta por João, 10 anos, filho de José, 64 anos, e Joana, 55 anos. João tem dois irmãos mais velhos, Joice, de 27 anos, e Jonathan, de 32 anos, que não moram na residência da família. Os pais possuem um minimercado junto a sua residência. João foi diagnosticado com Rabdomiossarcoma aos seis anos de idade, com metástase pulmonar, hepática, intestinal e óssea. Já realizou tratamento cirúrgico, quimioterápico injetável e oral. O Ecomapa (Figura 2), que demonstra as relações e vínculos da Família 02, foi desenhado por João, com o auxílio dos outros participantes.

Figura 2 - Ecomapa da família 02. 
Vínculos do binômio criança-família antes e após o diagnóstico de câncer infantil | 10

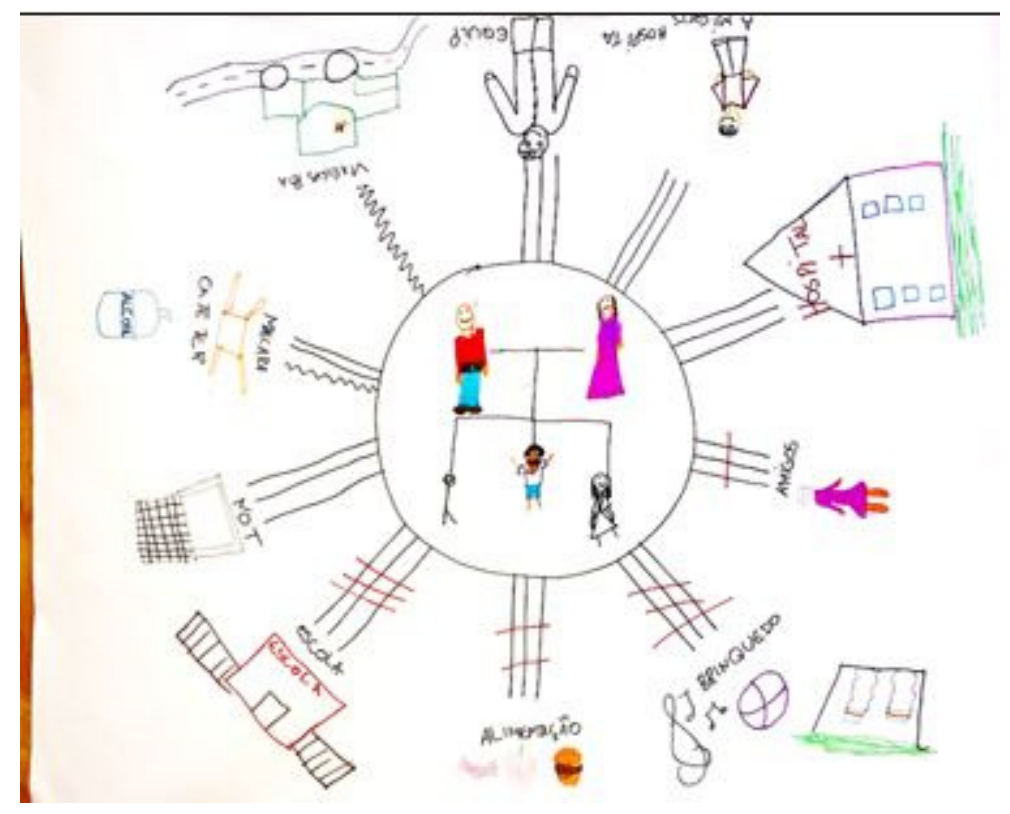

A Família 02 representou no Ecomapa o vínculo estressante com as viagens para Porto Alegre (RS) para realizar o tratamento. Além dessa questão com as viagens, João demonstrou como sendo estressante o vínculo que criou com a máscara e o álcool gel, devido à imunidade baixa e os cuidados com o cateter. Além disso, o vínculo com a escola teve que ser interrompido e alguns amigos o visitavam com pouca frequência. Agora, numa fase em que está com a imunidade mais alta, as brincadeiras com os amigos estão sendo retomadas aos poucos.

As AL relacionadas às brincadeiras e aos jogos foram restritas na rotina da Família 02. José contou que gostava muito de levar João na praça para brincar e jogar futebol, mas que, após o diagnóstico, esse foi um vínculo que teve de ser totalmente interrompido. Esse vínculo com atividades ao ar livre foi trocado por jogos eletrônicos no computador e no celular.

\section{Família 03}

A Família 03 é composta por Mateus, 11 anos, sua mãe, Marta, 33 anos, do lar, o pai, Marco, 32 anos, segurança, e a irmã de seis meses, Mariana. Mateus foi diagnosticado com Leucemia Linfóide Aguda (LLA) em 2016 e está em tratamento desde então. Além do 
11 | Rockembach JA, Muniz RM, Barboza MCN, chiavon AB, Pinto BK, Neves FB

diagnóstico de LLA, Mateus é portador de Síndrome de Down e a mãe diz que o menino, desde pequeno, frequenta uma escola especial, mas que não desenvolveu habilidades para desenhar. Por esse motivo, na construção do Genograma e do Ecomapa Mateus fez alguns símbolos e pediu para a mãe desenhasse o que ele queria. No desenho da Família 03, Marta representou os homens com triângulos e as mulheres com círculos. Os vínculos da Família 03 estão representados no Ecomapa (Figura 3):

Figura 3 - Ecomapa família 03.

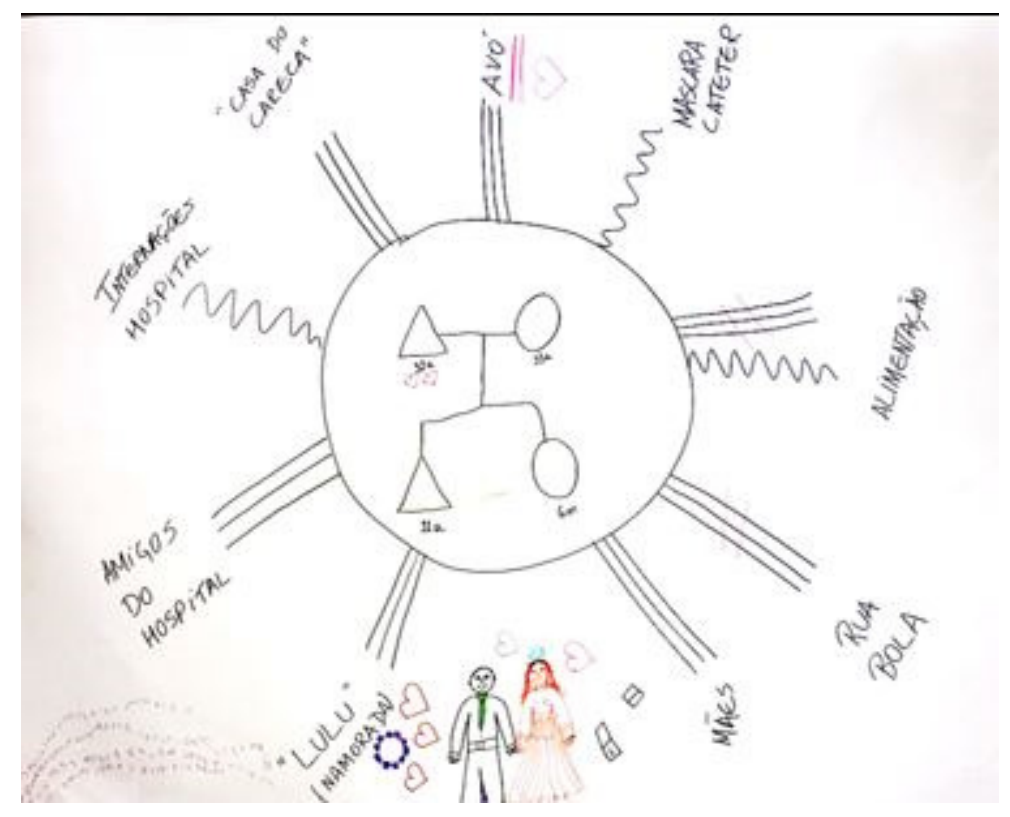

Mateus e Marta colocaram no Ecomapa o vínculo de estresse com as internações e os longos períodos fora de casa. Marta diz que ficava longe do marido por muito tempo porque Marco trabalha, não podendo acompanhá-los, e Mateus relata que sente muita falta do pai. Outro vínculo estressante para a família é fazer com que Mateus use a máscara facial quando está com a imunidade baixa após as sessões de quimioterapia. Além disso, a mãe falou o quanto se preocupa com os cuidados com o cateter do filho, já que tem medo de que ele o desloque e precise passar por um novo procedimento. Por esse motivo, algumas brincadeiras que Mateus costumava fazer foram parcialmente interrompidas, como brincar na rua e jogar bola. 
A Família 03 trouxe o vínculo forte que criou com a "Casa do Careca” que é como Mateus chama o Hospital e a Casa de Apoio que ficavam em Porto Alegre (RS). Pode-se perceber que, de forma lúdica, Mateus criou novos significados para a doença e a hospitalização. Mateus falou de forma muito carinhosa de sua amiga "Lulu”. Eles se conheceram na escola de educação especial que ele frequentava e ficaram muito amigos desde então. Marta contou que Lulu é a única amiga que Mateus manteve mesmo depois do diagnóstico, que ela sempre o visita e que brincam muito.

\section{Família 04}

A Família 04 é composta por Rafael, de oito anos, diagnosticado com Leucemia Mielóide Aguda (LMA) em janeiro de 2017, sua mãe Raquel, 53 anos, do lar, o pai Roberto, 67 anos, aposentado, e suas irmãs, Renata, 27 anos, Raissa, sete anos e Rita, quatro anos. Participaram da coleta de dados Rafael, Raquel, Raissa e Rita, sendo que Rafael desenhou o Ecomapa (Figura 4).

Figura 4 - Ecomapa família 04.

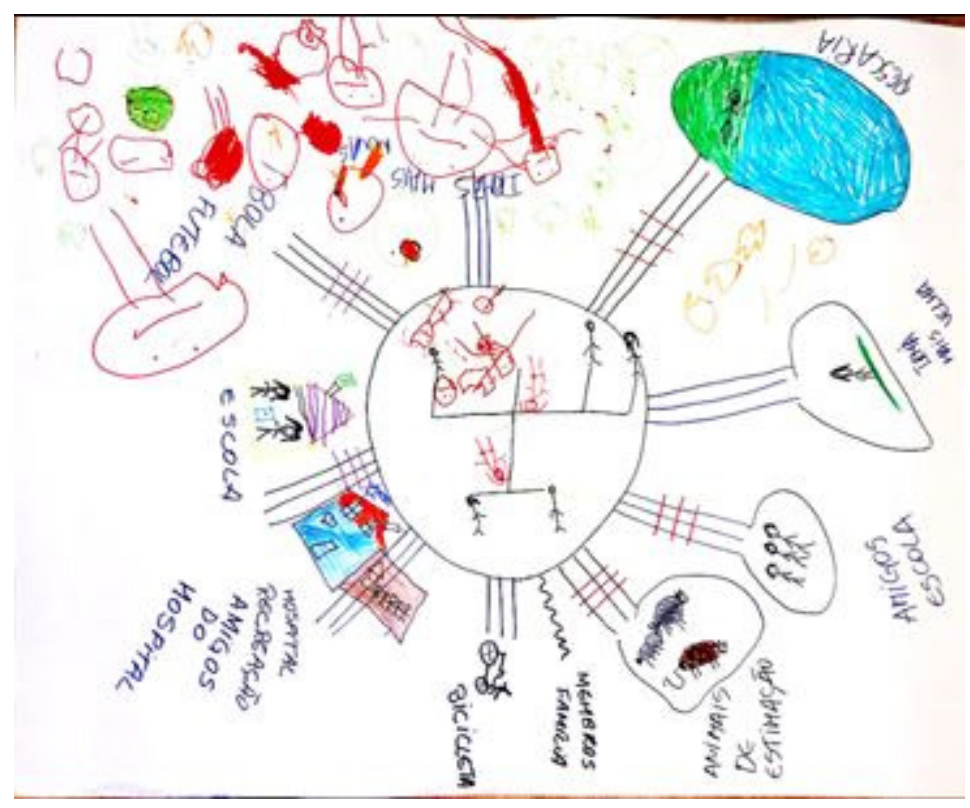

Devido às restrições do tratamento e à imunidade baixa, Rafael brinca somente com suas irmãs adaptando as brincadeiras, e Raissa e Rute cuidam para que ele não se machuque. O 
13 | Rockembach JA, Muniz RM, Barboza MCN, chiavon AB, Pinto BK, Neves FB

vínculo com outras crianças foi totalmente interrompido, uma vez que ele deixou de frequentar a escola após o diagnóstico.

Desse modo, devido à imunidade baixa de Rafael, a Família 04 precisou se desfazer dos animais de estimação. As crianças tinham um vínculo muito forte com os dois gatos e o cachorro da família, com quem brincavam diariamente. O vínculo teve de ser rompido, mas as crianças guardam fotografias com os animais, mostrando-as de forma afetuosa durante a construção do Ecomapa.

Além desse vínculo rompido, Rafael representou, no Ecomapa, as restrições relacionadas às duas atividades das quais gosta muito: futebol e pescaria. Raquel contou que Rafael sempre gostou muito de pescar e que seu tio sempre o levava aos finais de semana, tendo sido esse o vínculo de que Rafael sente mais falta.

\section{Família 05}

A família 05 é composta por Artur, nove anos, a mãe Ana, 39 anos e o padrasto Alberto, 38 anos. Os pais de Artur separaram-se quando ele ainda era pequeno e Artur tem um vínculo muito forte com Alberto. O menino foi diagnosticado com Leucemia Mielóide Crônica (LMC) em 2014, iniciando o tratamento com quimioterapia e, em julho de 2016, realizou um transplante de medula óssea. Artur desenhou o Ecomapa (Figura 5), colocando no centro a sua família, composta por ele, por sua mãe e seu padrasto.

Figura 5 - Ecomapa da família 05. 


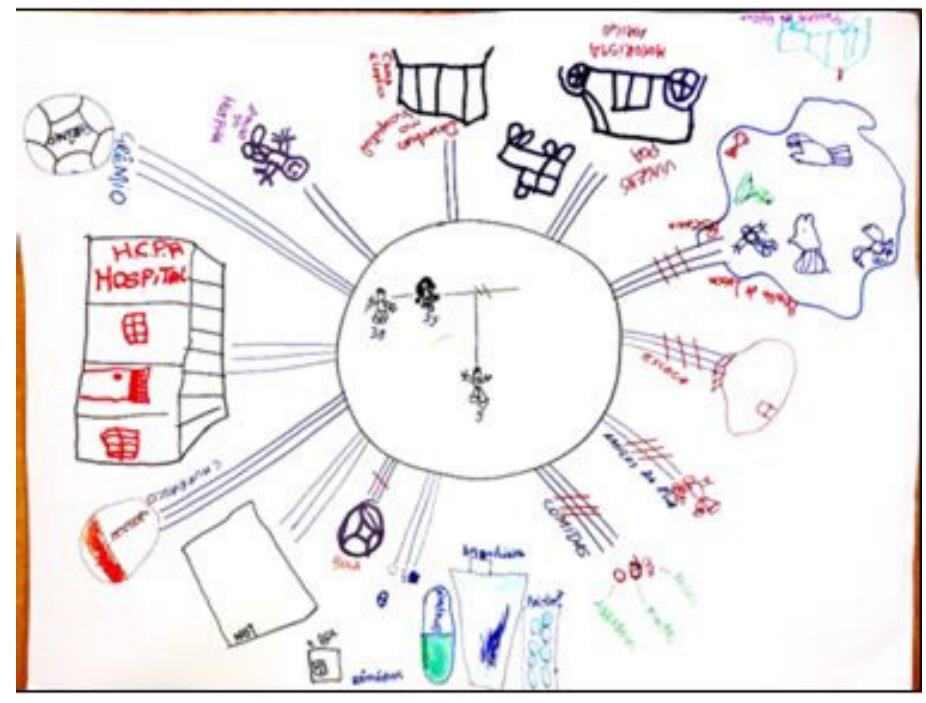

Como vínculos fortes criados após o diagnóstico de Artur, foram representados o hospital e os medicamentos. Artur contou os medicamentos que toma, sabendo o nome de todos e como cada um ajuda em sua doença. O menino demonstrou conhecimento acerca das restrições relacionadas ao seu tratamento e apresentou, no Ecomapa, o vínculo que teve que ser interrompido com determinados alimentos, como nozes, amendoim e chimarrão.

Outro vínculo forte trazido pela Família 05 são as viagens para Porto Alegre (RS). Artur contou que ficou muito amigo de um motorista da prefeitura que sempre o levava. Acerca das questões que envolvem as internações e viagens, Ana trabalhava em uma fábrica de doces e teve que parar após o diagnóstico de seu filho uma vez que tinha que acompanha-lo.

Artur contou que gosta muito de desenhar, reproduzindo, em seu Ecomapa, os desenhos que fazia nos períodos em que estava internado no hospital. Desenhava coisas das quais sentia saudade e vontade de fazer, por exemplo, pular em cama elástica, andar a cavalo e jogar futebol em um campo na frente de sua casa. Também desenhava carros de polícia, pois sonha em ser policial. Durante o período de internação, o menino disse que fez amigos no hospital, mas que não brincava muito enquanto estava internado, limitando-se a um vínculo forte com jogos eletrônicos no computador. 
15 | Rockembach JA, Muniz RM, Barboza MCN, chiavon AB, Pinto BK, Neves FB

Desde que foi diagnosticado, Artur teve de interromper o vínculo com a escola e com os amigos da rua. Após o diagnóstico, o menino contou que se sentia muito triste, pois ficava olhando pela janela enquanto os amigos da rua brincavam e jogavam bola.

Dentre as AL da Família 05, pescar, andar a cavalo e tomar banho de rio foram as atividades interrompidas desde o início dos sintomas de Artur. Ana contou que gostavam muito de ir para a zona rural e que seu filho gostava de pescar e tomar banho de rio, além de andar a cavalo.

\section{Família 06}

A Família 06 é composta por Sofia, cinco anos, sua mãe Sara, 34 anos, do lar, o pai Sergio, 38 anos, caminhoneiro e o irmão Samuel, de um mês de idade. Sofia foi diagnosticada com Osteossarcoma há cerca de dois anos.

Figura 6 - Ecomapa da família 06.

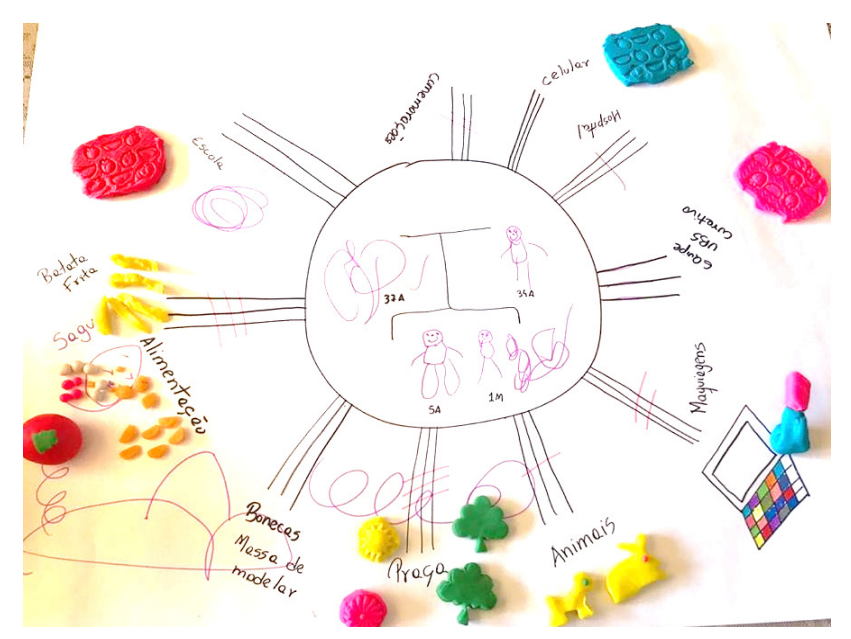

O Ecomapa foi desenhado pela própria Sofia, representando os vínculos da Família 06 com símbolos que fez com massa de modelar e desenho. A mãe escreveu e auxiliou a filha na realização da atividade. A Família 06 tinha como AL ir na praça juntos, gostavam de levar Sofia para brincar e passear. Essa era uma atividade muito presente na vida deles, sendo relatada como um vínculo forte que foi totalmente interrompido após o início do tratamento da filha. 
Vínculos do binômio criança-família antes e após o diagnóstico de câncer infantil | 16

A Família tem um cachorro e um coelho como animais de estimação. Embora tenha sido indicado que seria melhor para Sofia que se desfizessem dos animais, os pais optaram por apenas afastar um pouco a filha do convívio enquanto estava em uma fase mais debilitada do tratamento. Acreditam que o vínculo com os animais ajuda Sofia a encarar o momento que está vivenciando.

Após o diagnóstico, afastaram-se da família e dos amigos, e criaram novos vínculos com outras famílias de crianças com câncer, com a equipe do Hospital, e com a equipe de uma Unidade Básica de Saúde (UBS) que vai à residência da família para realizar curativos no cateter usado por Sofia. Além disso, a Família 06 relatou os vínculos de Sofia que foram interrompidos com a Escola que parou de frequentar e as restrições alimentares impostas pelo tratamento. Como vínculo forte da menina, indicou as massas de modelar, as brincadeiras com bonecas e os jogos no celular.

\section{Discussão}

O câncer é uma doença que vem permeada de sentimentos negativos e, portanto, receber tal diagnóstico é difícil para qualquer pessoa, principalmente para uma criança e sua família. ${ }^{11-12}$ Sabendo que a criança é uma integrante da família, quando ela está doente, a maioria dos outros membros é atingida, principalmente os seus cuidadores. ${ }^{13-14}$

Considerando as conversas com as famílias, constatou-se que o diagnóstico de câncer na criança trouxe sentimentos de medo, sobrecarga e estresse. Os pais precisaram mudar sua rotina, afastaram-se dos outros membros da família e mudaram a dinâmica familiar. Para eles, o câncer sobrepõe-se às outras atividades, levando a priorizarem a atenção e os cuidados com a criança doente. Assim, a família atravessa um período de adaptação, passando a ter necessidades especiais relacionadas à doença e ao tratamento. ${ }^{12,14}$

Desse modo, identificou-se que, após o diagnóstico de câncer na infância, a criança teve um rompimento de suas atividades escolares, e, consequentemente, das atividades lúdicas realizadas na escola e do convívio com os colegas. As crianças das Famílias 01, 03, 04 e 06 
tiveram suas atividades escolares interrompidas. Já as Famílias 02 e 05 apontam que, apesar de a criança não estar frequentando as aulas, as atividades escolares foram adaptadas para que ela não perdesse o ano letivo. Além da escolaridade, a criança com câncer encontra restrições em seu convívio social, uma vez que o câncer na infância interfere na prática de brincadeiras em grupo, nas relações sociais e interpessoais na comunidade em que está inserida. ${ }^{13-14}$

Para as famílias deste estudo, o convívio social das crianças foi parcialmente interrompido, uma vez que, com o tratamento e a imunidade baixa, ficam suscetíveis a infecções. Além disso, observa-se que as restrições ocorreram também quanto aos animais de estimação, mesmo que se saiba que a criança doente possa ter momentos de alegria ao brincar ao lado do seu animal. Embora as famílias e alguns profissionais mostrem-se receosos em relação ao convívio entre a criança e os animais, estudos apontam as vantagens de permitir tal prática desde que os devidos cuidados sejam tomados para evitar infecção. ${ }^{12-15}$

As atividades lúdicas, antes exercidas de forma intrínseca na rotina infantil, tornam-se difíceis para as crianças estudadas, pois, ao enfrentarem e a vivenciarem o câncer, necessitam adaptar-se a uma nova realidade. Além disso, o tratamento oncológico proporciona efeitos colaterais que fazem com que a criança não tenha disposição para brincar, além de diminuir o tempo livre para atividades de lazer. ${ }^{16}$ Em contrapartida, o lúdico, no âmbito hospitalar, foi preservado, mantendo-se como ferramenta estimulante para o desenvolvimento infantil. As AL durante as internações são compreendidas como fundamentais, pois entende-se a importância de preservar tais ações para que a criança não perca por completo as ferramentas que lhe propiciam crescimento cognitivo e emocional. ${ }^{17}$

Outro aspecto a ser destacado foi a possibilidade de a criança realizar atividades lúdicas estando liberada pela equipe médica, contudo, os familiares ainda encontraram resistência e medo de que ela se machuque durante a atividade. Desse modo, evidencia-se o quanto é necessário o esclarecimento de dúvidas dessas famílias, para que se empoderem e propiciem um 
ambiente de cuidados que vise o desenvolvimento infantil saudável e que a felicidade da criança seja superior a esse medo. Assim, é relevante o quanto uma família bem assistida pelos profissionais da área da saúde pode proporcionar um brincar saudável à criança com câncer, bem como ser uma família mais tranquila frente a esta AL.

No que se refere à seleção dos participantes da presente pesquisa, cabe uma consideração pelo fato de uma das crianças apresentar síndrome de Down, o que exige uma análise específica tendo em vista as questões relacionadas ao desenvolvimento infantil. Além disso, cabe ressaltar que o estudo analisou o impacto que o câncer na infância traz nas atividades lúdicas e no desenvolvimento infantil de forma qualitativa e a curto prazo. Salienta-se a relevância de estudos que analisem, também, esse impacto a longo prazo, procurando estabelecer uma comparação com crianças que não tiveram câncer infantil.

Como limitações do estudo cita-se a dificuldade em encontrar os participantes que obedecesse aos critérios propostos. Isso deve-se, principalmente, pelo fato de a pesquisa ser feita em uma cidade na qual não há o atendimento oncológico infantil como um serviço de referência em saúde.

\section{Conclusão}

Este estudo possibilitou a descrição e a análise dos vínculos da criança e da família, antes e após o diagnóstico de câncer, realizadas a partir do Genograma e Ecomapa. Mediante os dados, pode-se identificar que o câncer modifica, em diversos aspectos, a vida das crianças e de suas famílias, rompendo diversos vínculos. Dentre os principais destacam-se as atividades escolares, os momentos de lazer e o convívio com outras crianças, somados aos passeios ao ar livre, à mudança na alimentação e o distanciamento do animal de estimação. Contudo, diante dessas alterações e da adaptação ao novo contexto da vida, novos vínculos foram criados, bem 
como novas amizades surgiram dentro do ambiente hospitalar, em especial no espaço de recreação, local que promove o entretenimento sem restrições, sob orientações médicas.

Cabe salientar que a principal contribuição deste estudo para a prática com crianças com câncer e suas famílias está na importância do estímulo para a realização da AL, uma vez que é imprescindível para o desenvolvimento cognitivo e social da criança, além de tornar o ambiente mais leve e agradável. Destaca-se que as AL favorecerem a construção de vínculos seguros, e promovem saúde e bem-estar, além de colaborarem no enfrentamento e na adaptação da vida devido as mudanças que a doença estabelece. Entretanto, percebe-se, ainda, o quanto ela é pouco utilizada como ferramenta de trabalho pelos profissionais de saúde, aos quais se sugere a necessidade de uma capacitação e instrumentalização com esta metodologia de trabalho, a fim de evidenciar a sua importância e os efeitos positivos na vida das crianças e das famílias que vivenciam o diagnóstico do câncer infantil.

\section{Referências}

1. Instituto Nacional de Câncer José Alencar Gomes da Silva (INCA). Estimativa 2020: incidência de câncer no Brasil. Rio de Janeiro: INCA; 2019. 120 p.

2. Anjos C, Santo FHE, Carvalho EMMS. Childhood cancer in the family environment: an integrative review. REME Rev Min Enferm; 2015 jan-mar;19(1):234-40. doi: 10.5935/1415-2762.20150018

3. Lima KYN, Santos VEP. O lúdico como estratégia no cuidado à criança com câncer. Rev Gaúcha Enferm. 2015 jun;36(2):76-81. doi:10.1590/1983-1447.2015.02.51514

4. Vestena-Zilmer JG, Schwartz E, Burille A, Linck CL, Lange C, Eslabão A. Vínculos dos clientes oncológicos e familiares: uma dimensão a ser conhecida. Enfermería Glob [Internet]. 2012 [acesso em 2020 jul 20]. 2012;11(1):45-52. Disponível em: http://scielo.isciii.es/pdf/eg/v11n25/pt_clinica3.pdf

5. Mello DF, Ribeiro CSZ, Yakuwa MS, Furtado MCC, Scorzafave LGDS, Santos DD. Interações de suporte à primeira infância: uso do genograma e ecomapa. In: Anais do 8 Congresso Ibero-Americano em Investigação Qualitativa; CIAIQ 2019 jun 16-19; Lisboa: Lisboa CIAIQ; 2019;2: 179-184.

6. Santos AA, Santos JB, Lemos RG, Acioli FRD. Genograma e ecomapa: utilização no processo de cuidado na estratégia de saúde da família. Braz J Health Rev. 2019;2(4):3368-72. doi: 10.34119/bjhrv2n4-098 
Vínculos do binômio criança-família antes e após o diagnóstico de câncer infantil | 20

7. Yin RK. Pesquisa qualitativa do início ao fim. Porto Alegre: Penso; 2016.

8. BRASIL. Ministério da Saúde, Conselho Nacional de Saúde. Resolução no 466, de 12 de dezembro de 2012. Diretrizes e normas regulamentadoras de pesquisas envolvendo seres humanos. Diário Oficial da União: seção 1, Brasília, DF, n. 112, p. 59-62, 13 jun. 2013.

9. Conselho Federal de Enfermagem (COFEN). Código de Ética dos Profissionais de Enfermagem. Resolução COFEN 311/2007 [Internet]. 2007 [acesso em 2016 maio 05]. Disponível em: http://www.cofen.gov.br/resoluo-cofen-3112007_4345.html

10. Clarke V, Braun V. Using thematic analysis in Psychology. Qual Res Psychol [Internet]. 2006 [cited 2019 Jan 20];3(2):77-101. Available from: https://www.researchgate.net/profile/Virginia_Braun/publication/235356393_Using_thematic_analysis_in _psychology/links/00b7d52c9e6303d840000000/Using-thematic-analysis-in-psychology.pdf

11. Sulkers E, Tissing WJE, Brinksma A, Roodbol PF, Kamps WA, Stewart RE, et al. Providing care to a child with cancer: a longitudinal study on the course, predictors, and impact of caregiving stress during the first year after diagnosis. Psychooncology [Internet]; 2015 [cited 2018 Nov 10];24(3):318-24. doi: 10.1002/pon.3652

12. Rodrigues C, Cesar GS, Pacheco VC. Vivências e percepções dos familiares/acompanhantes frente ao tratamento oncológico em crianças e adolescentes. Redes [Internet]. 2018 [acesso em 2019 jan 20];1(1):14760. Disponível em: http://revistaredes.ielusc.br/index.php/revistaredes/article/view/16

13. Morais ES, Muniz RM, Viegas AC, Cardoso DH, Santos BP, Pinto BK. Vivência da família na sobrevivência ao câncer: entre esperança de cura e medo da recidiva. Rev Enferm Atenção Saúde [Internet]. 2019 [acesso em 2020 fev 18];8(1). Available from: https://www.researchgate.net/publication/335281893_VIVENCIA_DA_FAMILIA_NA_SOBREVIVENCI A_AO_CANCER_ENTRE_ESPERANCA_DE_CURA_E_MEDO_DA_RECIDIVA

14. Silva-Rodrigues FM, Bernardo CSG, Alvarenga WA, Janzen DC, Nascimento LC. Transição de cuidados para o domicílio na perspectiva de pais de filhos com leucemia. Rev Gaúcha Enferm; 2019; 40:19. doi:10.1590/1983-1447.2019.20180238

15. Almeida F, Nascimento A, Duarte A. Terapia assistida por animais: a experiência dos enfermeiros com o uso desta prática em um hospital oncológico. In: Anais do 50 Congresso Ibero-Americano em Investigação Qualitativa; CIAIQ 2016 jul 12-14; Porto. Porto CIAIQ; 2016;2:738-47.

16. Santos SR, Bispo TF, Morais RXDS, Amorim MNDS, Costa CSC, Siqueira SC. Atuação do enfermeiro nos cuidados paliativos à criança com câncer. Ref Saúde Fac Estácio Sá Goiás - RRS-FESGO [Internet]; 2019 [acesso em 2019 dez 12];2(3):61-4. Disponível em: http://revistaadmmade.estacio.br/index.php/rrsfesgo/article/viewFile/7183/47966155 
17. Rosa SF, Alves GA. Brinquedoteca: um estudo sobre as possibilidades pedagógicas no hospital regional de Ponta Porã-MS. Rev Magsul Educ Fronteira [Internet]; 2019 [acesso em 2019 nov 20];1 (1):13. Disponível em: http://bibmagsul.kinghost.net/revista2016/index.php/educfronteira/article/view/129

Editora Científica Chefe: Cristiane Cardoso de Paula

Editora associada: Nara Marilene Oliveira Girardon-Perlini

\author{
Autor correspondente \\ Michele Cristiene Nachtigall Barboza \\ E-mail: michelenachtigall@yahoo.com.br \\ Endereço: Barão de Santa Tecla, 788/301 \\ CEP:96010-140
}

\title{
Contribuições de Autoria
}

\section{1 - Juliana Amaral Rockembach}

Responsável por todos os aspectos do estudo, assegurando as questões de precisão ou integridade de qualquer parte do estudo.

\section{2 - Rosani Manfrin Muniz}

Aprovação da versão final do estudo a ser publicado.

\section{3 - Michele Cristiene Nachtigall Barboza}

Contribuições substanciais para a concepção ou desenho do estudo; construção e análise do estudo

\section{4 - Aline Blaas Schiavon}

Aquisição, análise ou interpretação de dados do estudo.

\section{5 - Bruna Knob Pinto}

Aquisição, análise ou interpretação de dados do estudo.

\section{6 - Franciele Budziareck das Neves}

Aquisição, análise ou interpretação de dados do estudo.

\section{Como citar este artigo}

Rockembach JA, Muniz RM, Barboza MCN, chiavon AB, Pinto BK, Neves FB. Vínculos do binômio criança-família antes e após o diagnóstico de câncer infantil. Rev. Enferm. UFSM. 2021 [Acesso em: Ano Mês Dia]; vol.11 e13:1-22. DOI:https://doi.org/10.5902/2179769242439 